\title{
MATERIAIS EDUCATIVOS DE VIGILÂNCIAS SANITÁRIAS: PERFIL DE PRODUÇÃO E CIRCULAÇÃO NO TEMA DOS ALIMENTOS
}

\author{
EDUCATIONAL MATERIALS FROM HEALTH SURVEILLANCE OFFICES: PROFILE OF PRODUCTION AND \\ CIRCULATION IN THE FOOD THEME
}

\section{MATERIALES EDUCATIVOS DE VIGILANCIAS SANITARIAS: PERFIL DE PRODUCCIÓN Y CIRCULACIÓN EN EL TEMA DE LOS ALIMENTOS}

\author{
Bianca Ramos Marins ${ }^{1}$ \\ Inesita Soares de Araujo ${ }^{2}$
}

Resumo $\mathrm{O}$ artigo traça um primeiro perfil de produção e circulação de materiais educativos produzidos e distribuídos por vigilâncias municipais do Estado do Rio de Janeiro, privilegiando o tema dos alimentos, no período 2008-2010. Para o mapeamento, consultamos bases de dados e acervos das coordenações de vigilância sanitária dos 92 municípios do estado. As vigilâncias sanitárias receberam carta-convite de participação na pesquisa, solicitando o envio de seus materiais educativos nas versões física ou digitalizada e o preenchimento de um questionário com questões de interesse da pesquisa: tema dos materiais, ano de produção e circulação, tiragem, origem institucional, formas de cooperação e circulação, justificativa para a produção. Trinta coordenações responderam e apenas nove enviaram materiais classificados como pertinentes à temática dos alimentos, delineando-se um cenário de pouco investimento nesse tema, em face da sua importância para a saúde pública. A análise apontou que na maioria dos materiais a abordagem das informações privilegia uma linguagem técnico-científica, distante da possibilidade de apropriação da população a que se destinam; grande desigualdade quanto a recursos de produção, com materiais de boa e má qualidade; e esforço de circulação circunstancial e sujeito ao processo político-administrativo e recorrentes situações de descontinuidade da ação.

Palavras-chave materiais educativos em saúde; comunicação e saúde; vigilância sanitária; alimentos.
Abstract The article traces a first profile of the production and circulation of educational materials produced and distributed by municipal health surveillance offices in the State of Rio de Janeiro, Brazil, focusing on the food theme, in 2008-2010 period. For mapping, we consulted databases and health surveillance coordinator collections from the 92 municipalities in the state. The health surveillance teams received a letter of invitation to participate in the survey. They were asked to submit physical or scanned versions of their educational materials and to fill out a questionnaire concerning issues of interest to the research: Theme of the materials, year of production and circulation, circulation, institutional origin, forms of cooperation and circulation, justification for the production. Thirty coordinators responded, and only nine sent materials rated as relevant to the food theme. This made it clear that investments in this area are very low, despite its importance to public health. The analysis pointed out that most information in the materials had been written in a technical-scientific language the population is unlikely to understand as intended; that there are great differences in production resources, with high-and low-quality materials, that there is a circumstantial circulation effort that is subject to the administrative political process, and that there are recurrent cases of action discontinuity.

Keywords Educational materials in health; communication and health; health surveillance; food. 


\section{Introdução}

Comunicar é uma ação inerente à sociedade humana, indispensável à sua existência. É pela comunicação que produzimos sentidos, os quais movem as relações sociais. Através dos tempos, muitos foram os meios e as tecnologias de que os homens se valeram para se comunicar, até os tempos atuais, em que as tecnologias da informação e da comunicação (TIC) propiciam a virtual instantaneidade dos contatos humanos.

Como qualquer outro setor de atividade, a saúde pública tem a comunicação como dimensão intrínseca aos seus processos, seja a comunicação entre as instituições e a população, seja a comunicação entre pares, intra e interinstitucional. Por um lado, pode-se afirmar que a qualidade da articulação entre os setores envolvidos nesse campo - estado, sociedade civil, profissionais de saúde, setor privado, mídia, academia, entre outros - é definida pela qualidade da comunicação praticada. Por outro lado, a fragilidade dessa articulação pode ser atribuída, entre outros fatores, ao distanciamento e à dificuldade de participação de alguns desses setores no processo de negociação nas questões da saúde (Marins, 2009).

Em relação à comunicação com o cidadão, o principal recurso das instituições, além da utilização da mídia e dos atuais canais de acesso direto (em geral, por telefone), são os chamados 'materiais educativos', pelos quais se oferecem à população informações sobre atitudes e comportamentos que devem ser adotados a bem da sua saúde. Esses materiais são também denominados recurso educativo ou de comunicação, material de apoio, material informativo, instrumento comunicacional, material audiovisual, material instrucional (Monteiro et al. 2006). Para seu desenvolvimento, são convocados saberes das áreas de Educação, Comunicação e Informação, além das áreas adstritas aos conteúdos específicos. No entanto, seu conteúdo e modo de utilização têm sido objeto de análises críticas, como a de Pimenta et al.:

A tentativa de simplificar as informações para o público leigo faz com que elas sejam, na verdade, banalizadas e desqualificadas, desconsiderando a posição do personagem e do espectador como cidadãos críticos. Faz-se 'tabula rasa' da população. Ela é o recipiente onde os órgãos oficiais depositam suas informações e receitas do que fazer ou não. Esse é o enfoque de educação sanitária dominante nos serviços e materiais educativos de saúde. Stotz (1993) define esse modelo como preventivo, abordando fatores de riscos comportamentais e individuais, ou seja, com a etiologia das doenças modernas. A eficácia da educação, neste enfoque, expressar-se-ia em comportamentos específicos, como deixar de fumar, aceitar vacinação, desenvolver práticas higiênicas, fazer exames periódicos etc. (Pimenta et al., 2006, p. 106). 
Para estas autoras, os materiais educativos deveriam ser capazes de promover o diálogo entre as diferentes áreas das ciências humanas e artes, encorajando o espírito crítico, tornando certos discursos explícitos, ao invés de reproduzir representações negativas e acríticas com base em posturas e sistemas discursivos hegemônicos de nossa sociedade.

Em estudo sobre impressos na área de educação em saúde, Freitas e Filho (2011) apontam que o enfoque da comunicação se caracterizou predominantemente pelo modelo unilinear e impessoal, sendo os receptores considerados meros consumidores de conceitos científicos; na maioria das vezes, a seleção do conteúdo desses materiais é de responsabilidade dos profissionais de saúde. Corroborando, Grippo e Fracolli (2008) descrevem que historicamente as propostas educativas em saúde têm focado a transferência de informações, de conhecimento com pouco impacto na realidade dos sujeitos.

Araujo (2006) enfatiza que os materiais deveriam adquirir relevância como prática comunicativa, não por ensinar comportamentos a serem aprendidos, mas por seu potencial em situar a população em relação às políticas públicas, aos programas, às rotinas, aos procedimentos. Entretanto, observa que não só isso não ocorre como ainda não são adequadamente contemplados aspectos elementares de qualquer ação de comunicação, como considerar a população a que se destina, a finalidade, a adequação da linguagem utilizada, o canal de circulação.

Monteiro et al. (2006) chamam a atenção para que ainda são pontuais as análises acerca da qualidade e repercussão do uso dos materiais educativos. Além de a prática avaliativa em comunicação ser de fato pouco disseminada no campo da saúde, o desenvolvimento e a avaliação especificamente de materiais educativos na área, como afirmam Pimenta et al. (2006), são atividades complexas que requerem cuidados, por demandarem discussões transdisciplinares.

Atualmente, vem se observando o crescente interesse público acerca de informações sobre temas como alimentos, nutrição e saúde. Nesse cenário amplia-se a cobertura da mídia na publicização de informações acerca desses temas e a relação com as doenças crônicas não transmissíveis (DCNTs) (Santos e Filho, 2002).

A saúde, em suas muitas dimensões e questões, vem sendo objeto de investimento acadêmico em sua interface com a comunicação. A partir dos anos 2000, esse movimento vem se intensificando, uma vez que o tema da alimentação vai emergindo como um dos que despertam mais atenção. A pesquisa de Araújo e Araujo (2013), analisando o conceito de promoção da saúde no programa Globo Repórter (Rede Globo de Televisão), apontou que, dentre os temas abordados, alimentação é um dos quatro assuntos recorrentes. Mas também identificou a predominância de um discurso sobre a promoção à saúde que privilegia abordagens da saúde próprias de uma 
perspectiva preventivista ou mesmo higienista, além de individualizar a responsabilidade pelos hábitos saudáveis.

O estudo de Serra et al. (2012) com dois grupos de jovens de configuração socioeconômica contrastante no Rio de Janeiro buscou compreender os processos vividos por eles no que concerne à saúde. O estudo dimensionou a participação dos discursos midiáticos na formação dos sentidos, tomando como caso a novela Malhação, da TV Globo, enfocando os temas sobre práticas alimentares e corpo. A principal conclusão apontou para uma participação de como os discursos midiáticos intervêm no padrão alimentar dos jovens, independentemente dos seus contextos de vida.

Nesse sentido, tem relevância o alerta de Chaud e Marchioni (2004), de que frequentemente são disseminados pela mídia conteúdos equivocados sobre alimentação, nutrição, suplementos alimentares e de emagrecimento. A divulgação da informação está mais pautada em critérios publicitários do que propriamente informativos sobre as características nutricionais acerca do produto, não possibilitando os esclarecimentos importantes para os cidadãos.

Essa é uma situação antagônica ao que recomenda a Política Nacional de Alimentação e Nutrição (Brasil, 2003, p. 22):

As ações dirigidas à adoção de práticas alimentares saudáveis deverão integrar todas as medidas decorrentes das diretrizes definidas nesta Política. Além das iniciativas inerentes a cada medida específica que vier a ser adotada, atenção especial deverá ser dada ao desenvolvimento de processo educativo permanente acerca das questões atinentes à alimentação e à nutrição, bem como à promoção de campanhas de comunicação social sistemáticas. Para isso, deverá ser buscado o engajamento das entidades técnico-científicas, dos estabelecimentos de ensino, dos veículos de comunicação, de entidades da sociedade civil e do setor produtivo (Brasil, 2003, p. 22).

E ainda:

A educação alimentar e nutricional contém elementos complexos e até conflituosos. Dessa forma, deverão ser buscados consensos sobre conteúdos, métodos e técnicas do processo educativo, considerando os diferentes espaços geográficos, econômicos e culturais. A promoção de práticas alimentares contemplará, também, iniciativas específicas dirigidas ao aleitamento materno, tendo prioridade, neste contexto, as mulheres em idade fértil (Brasil, 2003, p. 22).

A relação indissociável entre alimentação e saúde é reconhecida como direito social adquirido, assim como a missão da vigilância sanitária na promoção e proteção à saúde da população, por meio de ações capazes de minimizar ou prevenir riscos à saúde decorrentes da alimentação. A vigilância 
sanitária exerce atividades e detém responsabilidade nas três esferas de governo e diferentes níveis de gestão. À Agência Nacional de Vigilância Sanitária (Anvisa), órgão competente do Ministério da Saúde, cabe coordenar, supervisionar e controlar as atividades de registro, informações, inspeção, controle de riscos e estabelecimento de normas e padrões higiênico-sanitários. Essa atuação é compartilhada com o Ministério da Agricultura, Pecuária e Abastecimento (Mapa), os estados e os municípios, que integram o Sistema Nacional de Vigilância Sanitária, cabendo ao Mapa a regulamentação, registro e inspeção dos estabelecimentos produtores de origem animal, vegetal (produtos in natura) e indústrias de processamento de bebidas.

Essa interdependência de ações contribui para que a missão da vigilância sanitária seja alcançada, e o Estado tem uma função relevante na organização dos serviços de vigilância sanitária em cada instância de poder. Para Rangel-S, Marques e Costa (2007), a comunicação tem-se tornado um elemento fundamental no contexto da vigilância sanitária, não só na interação entre os diversos sujeitos nos diferentes espaços internos institucionais, de forma a garantir as ações das três esferas de governo, mas também na comunicação externa com a sociedade, setor regulado e profissionais de saúde.

A necessidade de se concretizar uma política de informação e comunicação em saúde também recebeu atenção na I Conferência Nacional de Vigilância Sanitária, em 2001. A relação entre democratização da informação, comunicação social e cidadania, percebida no contexto da produção de conhecimentos, teve destaque nos itens 207 a 215:

Os participantes da I Conferência Nacional de Vigilância Sanitária reafirmam o direito à informação acerca das ações de vigilância sanitária e reivindicam agilidade na resposta às suas demandas. Propõem a formulação e implementação de uma política de comunicação social na área, espaços gratuitos nos meios de comunicação e instrumentos a serem utilizados, considerando as possibilidades de construir uma consciência sanitária, ética e de cidadania (Brasil, 2001).

Em busca da construção de vias que possibilitem a circulação, democratização e interatividade da informação e comunicação no âmbito da saúde, Marques e Jesus (2007) relataram a experiência do Programa de Informação e Comunicação - Projeto de Comunicação do Sistema Estadual de Vigilância Sanitária do Rio de Janeiro, que mobilizou a parceria entre academia, representada pela Escola Nacional de Saúde Pública Sergio Arouca (Ensp), e os serviços, representados pelo Centro de Vigilância em Saúde da Secretaria Estadual do Rio de Janeiro (SES/RJ) na consolidação do processo de difusão da informação e pelo estabelecimento de canais de comunicação com a população, profissionais e instituições de saúde. Dentre esses canais inclui-se a página eletrônica do Centro de Vigilância Sanitária (CVS) da SES/RJ, desenvolvida 
para fornecer e recolher informações necessárias ao Sistema Estadual de Vigilância, desburocratizar o contato com o segmento regulado e elevar o nível de consciência da população. Esse programa também editou uma série de cartilhas temáticas e ainda pretende produzir programas de rádio sobre vigilância sanitária.

Outra experiência relatada por Marques e Jesus (2007) no âmbito da comunicação em saúde em busca da participação cidadã foi o Projeto VisaMobiliza. É uma experiência municipal desenvolvida pela Diretoria de Ações Descentralizadas de Saúde de Sete Lagoas, em Minas Gerais, em parceria com a Fundação Oswaldo Cruz, a Secretaria Municipal de Saúde de Baldim e a Escola de Saúde Pública do Estado de Minas Gerais. O objetivo desse projeto foi contribuir para a formação da consciência sanitária a partir da temática da esquistossomose, eleita por meio de diagnóstico realizado conjuntamente pelos diferentes atores sociais como um relevante problema de saúde pública. A intervenção foi desenvolvida mediante práticas de educação e comunicação baseada no planejamento estratégico, construída a partir do conhecimento social de cada comunidade, considerando o saber da população, respeitando sua cultura e o direito à informação.

Situando-se em meio a esse movimento, sobretudo seu lado que contempla a busca por um maior e mais sistematizado conhecimento sobre a prática de comunicação no âmbito da vigilância sanitária, a pesquisa, cujos resultados aqui apresentamos, buscou contribuir para a reflexão sobre a comunicação com a sociedade no âmbito da vigilância sanitária, por meio da avaliação de materiais educativos produzidos e/ou distribuídos por vigilâncias sanitárias municipais do Estado do Rio de Janeiro, contemplando o tema dos alimentos e fazendo um primeiro delineamento de seu perfil de produção e circulação.

A pesquisa, intitulada "Materiais educativos de vigilâncias sanitárias: perfil de produção e circulação no tema dos alimentos", contou com financiamento da Fundação Carlos Chagas Filho de Amparo à Pesquisa do Estado do Rio de Janeiro (Faperj). Não houve necessidade de avaliação por um Comitê de Ética em Pesquisa, por não se tratar de pesquisa envolvendo seres humanos.

\section{Metodologia e corpus analítico}

A pesquisa foi qualitativa e estruturada em três procedimentos: mapeamento e coleta dos materiais educativos, sistematização e análise qualitativa. O mapeamento foi feito por consulta a bases de dados e a acervos das coordenações de vigilância sanitária dos 92 municípios do Estado do Rio de Janeiro referentes à área de alimentos e nas gestões municipais de 2008 a 2010. O Núcleo 
de Planejamento e Desenvolvimento Institucional da Superintendência de Vigilância Sanitária da Secretaria de Saúde e Defesa Civil do Estado do Rio de Janeiro (NPDI/SVS/SESDEC) enviou às vigilâncias sanitárias municipais, por e-mail, uma carta-convite de participação na pesquisa. Os materiais deveriam ser enviados ao NPDI na forma física ou em versão digitalizada.

As coordenações municipais foram solicitadas a preencher um questionário intitulado "Instrumento de Avaliação do Material Informativo" com questões sobre: tema dos materiais, ano de produção e circulação, tiragem, origem institucional, formas de cooperação e circulação e justificativa para a produção, com espaço para outros dados não predefinidos.

O prazo para resposta foi de 45 dias a partir da data de emissão do convite. Findo o prazo, considerou-se que o corpus de análise seria formado pelos materiais recebidos.

\section{Sistematização e análise qualitativa}

A sistematização dos dados constou de descrição e categorização dos materiais, formando um perfil quantitativo dos impressos utilizados pelas vigilâncias municipais. $\mathrm{O}$ material foi classificado segundo origem geográfica e institucional, formato, tema, tiragem, ano de produção, formas de cooperação e circulação, além de justificativa para produção.

Quanto à análise, foram contempladas as seguintes dimensões: objetivo; destinatários; formas de circulação e conteúdo (abordagem conceitual, abrangência e densidade da informação e estrutura formal). As questões que orientaram o exame dos materiais procuravam obter informações tais como: o que se pretendia informar com aquele material; quais seus destinatários; por onde os materiais circularam e quais as modalidades de circulação; quais as concepções de Visa que emergiam do material, mas também quais as concepções sobre o destinatário. Em relação ao conteúdo informativo, qual a modalidade de relação entre o emissor e os potenciais leitores; se as informações que continham estavam corretas, se havia lacunas ou excesso de informação e se os conceitos-chave eram suficientemente elucidativos; ainda, se os dados de autoria estavam oferecidos com clareza. Em relação à estruturação formal textual, buscou-se avaliar as imagens, se existentes: elas complementaram a informação ou apenas cumpriram o papel de ilustração? Sua nitidez permitiu uma apreensão satisfatória? Qual a legibilidade do texto, considerando o tipo, o tamanho e a cor das letras? A diagramação favorece a leitura ou a dificulta? Ainda se observou a forma do material, considerado pelo ângulo da inovação. 


\section{Resultados e discussão}

Dos 92 municípios consultados, apenas trinta enviaram resposta no prazo estipulado pela pesquisa. Desses, dois informaram que os materiais utilizados eram oriundos da Anvisa e da SES-RJ, mas não os enviaram para análise. Três municípios responderam que nas inspeções fazem orientações verbais, com base em Manual de boas práticas de fabricação, dos serviços de alimentação, e um município informou que o material informativo se encontrava em processo de confecção.

Dos 24 municípios que responderam, 13 enviaram materiais sem relação direta com alimentos. Assim, foram nove os municípios que tiveram os materiais analisados: Barra do Piraí, Cachoeira de Macacu, Pinheiral, Porto Real, Resende, Rio Bonito, Rio de Janeiro, São João de Meriti e Volta Redonda.

\section{Resultados da sistematização}

Os materiais versam sobre boas práticas de manipulação, conservação e cocção. As informações desses materiais foram selecionadas como estratégias relevantes a serem adotadas por produtores e consumidores na tentativa de minimizar a contaminação dos alimentos.

O Quadro 1 mostra o resultado da sistematização dos dados extraídos da planilha de avaliação. Os materiais educativos na área de alimentos produzidos pelas vigilâncias sanitárias municipais do Rio de Janeiro apresentaram as seguintes características:

Quadro 1

\begin{tabular}{|c|c|}
\hline Critério analítico & Comentário \\
\hline Temas dos materiais & $\begin{array}{l}\text { Os temas dos materiais versam sobre: orientação ao comércio quanto à forma de proceder com os } \\
\text { alimentos; higiene para manipuladores de alimentos; forma de higienizar os vegetais consumidos } \\
\text { crus; informes orientadores aos consumidores de bar e lanchonete, restaurantes, padaria e } \\
\text { confeitaria, self service; laticínios e frios, peixaria, sacolão, açougue; cuidados básicos sobre a compra } \\
\text { de alimentos; orientação ao comércio de alimentos; procedimentos para segurança alimentar } \\
\text { destinados ao comércio de alimentos; orientação para instalação de barracas em períodos de } \\
\text { festejos municipais; orientações a comerciantes e consumidores sobre o consumo de alimentos de } \\
\text { origem animal; informações sobre alimentação saudável dirigida ao cidadão; orientação ao } \\
\text { cidadão sobre intoxicação alimentar. }\end{array}$ \\
\hline
\end{tabular}




\section{Continuação - Quadro 1}

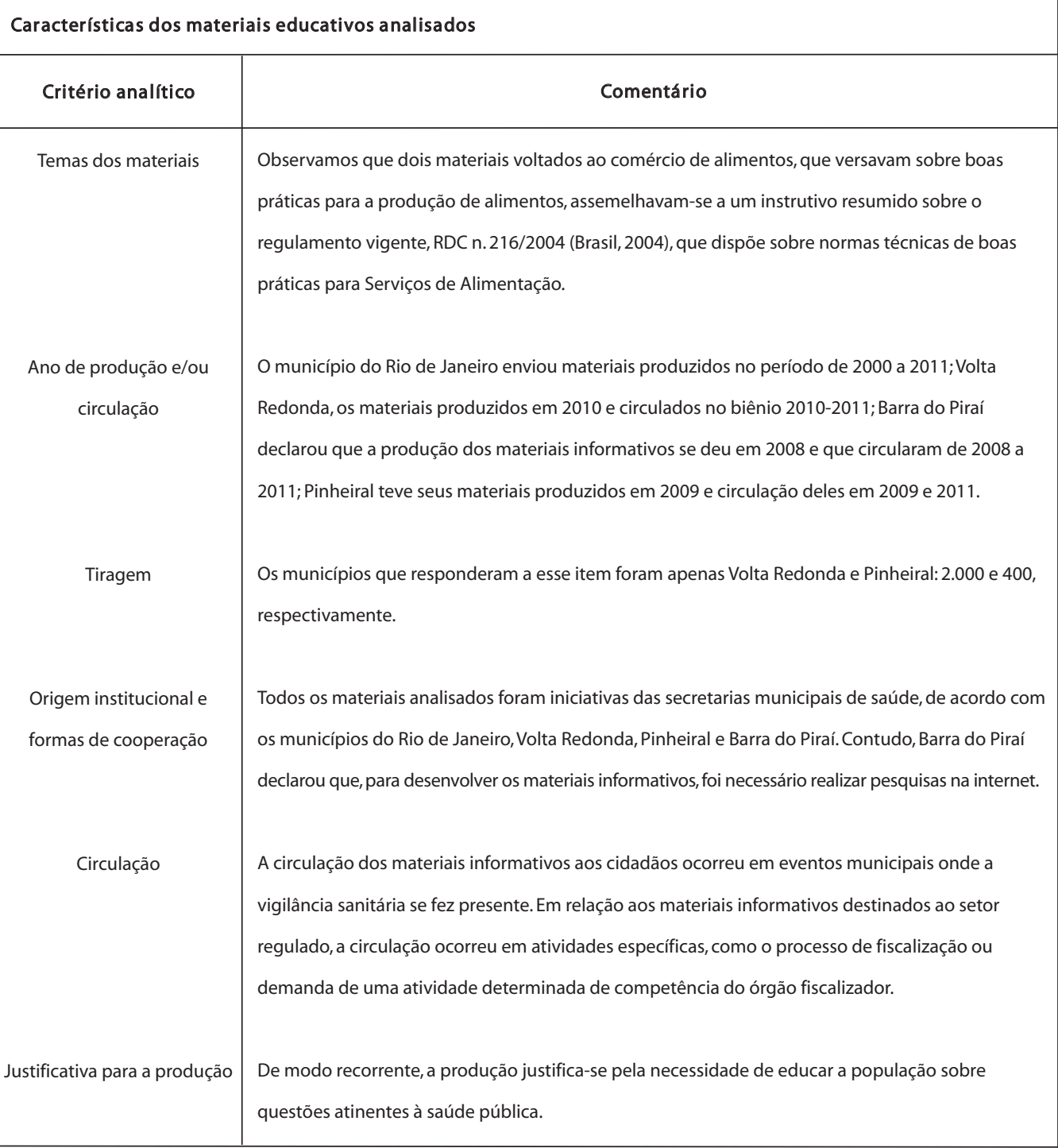

Fonte: Os autores.

O "Instrumento de Avaliação do Material Informativo" enviado às vigilâncias sanitárias municipais foi preenchido apenas pelos municípios do Rio de Janeiro, Volta Redonda, Barra do Piraí e Pinheiral. Maior adesão ao preenchimento desse instrumento poderia ter subsidiado melhor as análises; contudo, algumas lacunas de informação foram minoradas pelo envio dos materiais informativos por outros municípios.

Quanto ao formato, predominaram os folhetos (11), mas também se verificou a opção por livretos (3), cartazes (9) e filmes na forma de vídeo ou DVD (1). 
Contudo, o vídeo não fez parte do corpus de análise, pois se tratava de um material sobre a missão institucional. Essa configuração quanto ao formato dos impressos corresponde ao cenário que se verifica em outros temas na área da saúde, apontando para os formatos mais convencionais, sem nenhuma inovação, e refletindo o baixo investimento financeiro no desenvolvimento de novas tecnologias de comunicação.

\section{Resultados da análise}

A análise será apresentada segundo as cinco dimensões avaliadas (objetivo, destinatário, forma de circulação, conteúdo, estruturação textual) e a avaliação final do pesquisador. Queremos antes, porém, comentar o baixo número de materiais obtidos no levantamento inicial. O relatório de pesquisa intitulado "Gestão da Comunicação aplicada à vigilância em saúde: percepção dos gestores" (Brasil, 2007) revela que, na opinião dos gestores de saúde das três esferas de governo, as ações de comunicação têm origem na esfera federal e que os estados e municípios têm pouca iniciativa de planejamento, bem como a falta de integração diminui significativamente a operacionalização na circulação e adequação dos materiais de campanha às especificidades regionais. De fato, esse é um fenômeno que se observa largamente na saúde: a centralização pelo Ministério da Saúde da produção dos materiais de comunicação e a consequente desmobilização das instâncias locais para a produção de seu próprio material (Araújo, Cardoso e Murtinho, 2010). Dessa forma, aquilo que não está na pauta ministerial como prioridade de investimento acaba ficando sem cobertura no que tange aos materiais de apoio à ação dos técnicos. Outras razões podem estar localizadas na falta de pessoal qualificado para a tarefa (também resultante da concentração das equipes de comunicação em poucos núcleos mais centrais) e/ou na maior tradição no âmbito da vigilância de uma comunicação face a face, sem mediação de impressos ou audiovisuais. Passemos, portanto, à análise dos materiais obtidos.

\section{Quanto aos objetivos e destinatários}

Os materiais têm como objetivo orientar manipuladores, bem como consumidores de alimentos ou estes, na ausência daqueles a respeito das medidas higiênico-sanitárias de segurança do produto. De acordo com a lei n. 11.346, de 15 de setembro de 2006, que define o Sistema Nacional de Segurança Alimentar e Nutricional (Sisan), visando assegurar o direito humano à alimentação adequada, em seu art. $3^{\circ}$, afirma que: 
A segurança alimentar e nutricional consiste na realização do direito de todos ao acesso regular e permanente a alimentos de qualidade, em quantidade suficiente, sem comprometer o acesso a outras necessidades essenciais, tendo como base práticas alimentares promotoras de saúde que respeitem a diversidade cultural e que sejam ambiental, cultural, econômica e socialmente sustentáveis (Brasil, 2006).

Nos materiais, sobressai-se a preocupação em informar sobre os contaminantes alimentares. Essa ênfase pode ter relação com a necessidade de minimizar a incidência das doenças transmitidas por alimentos (DTAs), que também podem ter como agentes causadores substâncias de origem química e física.

A ocorrência de Doenças Transmitidas por Alimentos (DTA) vem aumentando de modo significativo em nível mundial. Vários são os fatores que contribuem para a emergência dessas doenças, entre os quais destacam-se: o crescente aumento das populações; a existência de grupos populacionais vulneráveis ou mais expostos; o processo de urbanização desordenado e a necessidade de produção de alimentos em grande escala. Contribui, ainda, o deficiente controle dos órgãos públicos e privados no tocante à qualidade dos alimentos ofertados às populações. (Brasil, 2010).

Na pesquisa, observamos um predomínio de materiais direcionados aos consumidores e cidadãos, totalizando 16; tendo produtores, comerciantes e manipuladores de alimentos como destinatários, identificamos seis, que apresentavam informações de caráter técnico àqueles que de algum modo beneficiam os alimentos, e um cartaz destinado a comerciantes e consumidores.

\section{Quanto à forma de circulação}

Em relação à circulação dos materiais, os municípios informaram que geralmente ocorre nas palestras sobre a missão do serviço de vigilância sanitária, inspeções sanitárias a estabelecimentos produtores de alimentos, conferências municipais de saúde e eventos festivos, como festas municipais e jogos pan-americanos, esta última exclusiva do município do Rio de Janeiro. Isso aponta para um uso convencional, que explora pouco a potencialidade dos materiais e que talvez esteja associado à dificuldade de articular os eventos para a divulgação com a disponibilidade dos materiais informativos. Outro fator, que pode ser levado em consideração como codeterminante dessa precariedade, é a falta de disponibilidade de recursos financeiros permanentes que viabilizem a produção continuada e atualizada dos materiais.

Esse cenário pode retratar o caráter pontual das ações de informação e comunicação em saúde, ao mesmo tempo que pode representar um indício dos baixos recursos investidos nessas ações. 


\section{Quanto ao conteúdo}

A abordagem técnico-sanitária se fez presente em todos os materiais analisados. Em alguns, observamos prescrições comportamentais, como: "Não cuspir no chão no local de trabalho" ou "Não provar alimentos com talheres e colocá-los de novo na panela, sem antes lavá-los". Embora a missão da vigilância sanitária justifique de certo modo essas preocupações, não se pode esquecer que essas orientações constroem a imagem de um leitor que precisa ser educado quanto a comportamentos sanitários. Tal prática discursiva encontra correspondência no modelo de comunicação dominante na saúde, com foco na indução comportamental e numa abordagem meramente preventivista.

Nessa concepção, o que se denomina 'comunicação em saúde' aproxima-se do que seria um 'adestramento': ao apenas ditar atitudes e comportamentos, contribui-se para formar uma prática restrita no tempo e no espaço caracterizado pelos materiais, limitando o desenvolvimento da capacidade de reflexão das pessoas, que permitiria o desenvolvimento sustentável de uma consciência de vigilância em saúde.

Ademais, a prática de uma comunicação meramente transferencial acaba por excluir do cenário público a discussão proativa entre órgãos gestores e demais setores da sociedade na busca de soluções para as demandas de saúde. Assim, reafirma-se a definição de apenas duas competências, cabendo aos órgãos gestores a informação e à sociedade a adesão. Esse cenário sugere que, após a adesão às normas prescritas como ideais, os riscos à saúde são minimizados. O que está implícito nessa elaboração é uma relação mecânica de causa e efeito entre comportamentos moldados e riscos eliminados, o que - já se sabe largamente - não é o que ocorre.

Diferentes autores, como Vasconcellos-Silva, Rivera e Rozemberg (2003), Araújo (2006), Castiel e Vasconcellos-Silva (2006), já evidenciaram os problemas na elaboração de materiais informativos em saúde. Um deles é a tendência ao doutrinamento do destinatário antes mencionada. O outro diz respeito à possibilidade de apropriação, pelo leitor, do conteúdo do material. Embora não se possa omitir que a comunicação clara dos conceitos de saúde, em geral oriundos do campo científico, não é tarefa simples - e até por isso mesmo -, a produção textual exige um constante esforço e cuidado para que os significados técnico-científicos sejam apropriados pelo destinatário.

Os materiais analisados apresentaram variações entre uma linguagem simples ("Não provar alimentos com talheres e colocá-los de novo na panela, sem antes lavá-los") e o uso de linguagem técnica:

Alimentos prontos e semiprontos, após seu preparo, devem ser conservados em vitrines ou estufas com aquecimento superior a $60{ }^{\circ} \mathrm{C}$ por no máximo 6 horas (salgadinhos, empadas, rissoles, etc.), ou sob refrigeração, em balcões ou vitrines 
frigorificadas a temperatura de $4{ }^{\circ} \mathrm{C}$ ou inferior por no máximo 5 dias (saladas, sanduíches naturais, pudins, etc.).

Algumas vezes, a linguagem produz informações inócuas, pela forma ou conteúdo inespecífico ou inacessível para grande parte das pessoas ("Adotar técnicas de higienização adequada"; "Usar corretamente o sanitário"; "As bactérias reproduzem-se em progressão geométrica, de modo que, em algumas horas, surgem milhares de descendentes: filhos, netos, bisnetos e assim sucessivamente").

Apesar dessas limitações, as informações foram apresentadas de forma correta. Entretanto, alguns materiais não explicitavam conceitos-chave: “(...) Alguns microrganismos patogênicos (...)”, sendo a compreensão destes precedentes para o bom entendimento da informação.

De modo geral, a linguagem apresenta-se com um tom prescritivo e autoritário, e os conteúdos são descritos em tópicos e palavras no imperativo. "Observe", "verifique", "proibido", "obrigatório" e "denuncie" são palavras frequentemente utilizadas nos materiais. "Não consuma alimentos em locais que não zelam pela higiene." "Sr. Consumidor, exija higiene na manipulação dos alimentos." "É proibido aos funcionários fumar durante o serviço." "Denuncie a presença de animais no estabelecimento."

A ideia que emerge da leitura é a de subalternização do destinatário, que deve obrigatoriamente adotar uma determinada conduta que minimizará ou sanará os riscos à saúde. A possibilidade de uma interlocução fica restrita à disponibilização de telefones do serviço de fiscalização sanitária e às ouvidorias. Todavia e contraditoriamente, em 11 materiais é conferida importância ao papel a ser desempenhado pelo cidadão quanto à ação dos órgãos de vigilância sanitária. "Exija os seus direitos, você é o principal fiscal"; "Ajude a fiscalização sanitária a proteger sua saúde. Verifique a qualidade dos alimentos"; "Todos têm direito à saúde." Aqui, a imagem proposta do destinatário é a de coadjuvante da ação pública, mas também de sujeito de direitos, que devem ser, porém, garantidos por uma ação individual e individualista.

Os dados de autoria fazem menção e legitimam a ação da secretaria de saúde municipal e serviço de vigilância sanitária, principalmente, quando buscam aproximar e valorizar as ações executadas por aquele serviço como estratégias de promoção à saúde.

Essa constatação coaduna com os resultados publicados pela pesquisa realizada com gestores de saúde (Brasil, 2007), ao apontar a dificuldade de ações integradas com profissionais da área de comunicação, que poderiam auxiliar na relação com a mídia, mas também com a população, de maneira que as informações não sejam superestimadas ou subestimadas. 


\section{Quanto à estruturação textual e qualidade da impressão}

Os municípios de maior porte e com mais recursos financeiros produziram materiais que dispunham de imagens com melhor qualidade gráfica, em comparação aos produzidos por municípios menores. Em alguns materiais, as imagens utilizadas apresentaram baixa nitidez. Em outros, a disposição dos textos é 'poluída', dificultando a leitura. Isso foi observado nos materiais destinados aos manipuladores de alimentos; o contrário ocorre quando o destinatário é o cidadão: nestes, priorizam-se as imagens em detrimento do texto.

Em relação à qualidade gráfica, observamos que os materiais informativos do município do Rio de Janeiro, comparados aos demais municípios, apresentaram-se num patamar superior, tanto pela maior nitidez quanto pelo investimento na arte gráfica.

\section{Considerações finais}

Esta pesquisa deflagrou uma reflexão sobre a área da comunicação em saúde, quando no contexto da vigilância sanitária, e apontou limitações e fragilidades na produção de materiais informativos no campo da vigilância sanitária de alimentos nos municípios do Estado do Rio de Janeiro.

O número de materiais obtidos nas vigilâncias foi muito abaixo do necessário para se proceder a uma análise mais completa. Por isso, devem-se pôr em perspectiva os resultados e as análises aqui aportados, muito embora eles corroborem resultados de estudos anteriores. Por exemplo, é de se supor que as dificuldades identificadas podem ter relação não apenas com os baixos recursos financeiros para investimentos nas ações de comunicação, mas também com a difícil articulação de saberes entre técnicos das áreas de comunicação e da saúde.

Por outro lado, o baixo número de respostas e de materiais disponíveis é, por si mesmo, um resultado de pesquisa que aponta para uma situação bastante aquém do que seria desejável. Atualmente, é crescente a consciência do papel que a informação e a comunicação desempenham na possibilidade de uma saúde de qualidade para a população. Sendo os materiais informativos a estratégia comunicativa mais frequente das instituições de saúde, a dificuldade que observamos no âmbito das vigilâncias municipais é preocupante e pede novos estudos que permitam localizar as causas da precariedade observada no contexto do Estado do Rio de Janeiro.

Ao mesmo tempo em que observamos essas fragilidades nos municípios analisados, um relatório de pesquisa sobre o crescimento de DTAs (Brasil, 2007) revelou que, de acordo com a opinião dos gestores federais em saúde, as 
estratégias e os meios de comunicação são insuficientes e que há necessidade da produção de materiais de ensino para públicos segmentados, como profissionais de saúde, e de aproximação às necessidades da população. Temos então uma discrepância entre o que pensam os gestores federais e o que ocorre no nível estadual, acrescentando-se outras questões ao cenário estudado.

Certamente o desenvolvimento de materiais informativos não é uma atividade simples. Além de interesses políticos, financiamento e uma determinada demanda em saúde, faz-se necessária articulação de diferentes áreas do conhecimento, prática ainda hoje pouco comum nos serviços públicos. Mas sua importância, atualmente, seja nas modalidades mais tradicionais, seja naquelas que lançam mão dos recursos das tecnologias digitais, pede que sejam ultrapassados os limites e mais bem explorado seu potencial. Não se pode mais continuar a desenvolver e usar materiais com o único objetivo de prescrever comportamentos de forma autoritária, reduzindo assim o imenso potencial das práticas comunicacionais, partindo das próprias necessidades sentidas pela população, em favorecer um processo reflexivo. Processo este que, quando incorporado a estratégias planejadas e integradas, pode favorecer uma melhor tomada de decisão no gerenciamento do risco sanitário.

Entretanto, as questões que se apresentaram até aqui são da ordem da produção e circulação dos materiais, que não serão nunca devidamente atendidas se não forem contempladas aquelas da ordem da apropriação (ou recepção, como são mais conhecidas). E considerar a apropriação é compreender que materiais não podem ser apenas um instrumento de transmissão de conhecimentos, de uma fala autorizada, mas elementos mediadores na interlocução entre sociedade e Estado.

\section{Colaboradores}

Bianca Ramos Marins foi responsável pela idealização da proposta, coleta e análise e discussão dos dados e elaboração do artigo. Inesita Soares de Araujo foi responsável pela orientação metodológica da pesquisa, discussão e revisão do artigo em todas as suas etapas e dimensões textual, estrutural e conceitual. Declaramos não haver conflitos de interesse. 


\section{Agradecimentos}

À Fundação Carlos Chagas Filho de Amparo à Pesquisa do Estado do Rio de Janeiro pela bolsa de pesquisa de professor-pesquisador a Bianca Ramos Marins na Escola Politécnica de Saúde Joaquim Venâncio.

A Ana Lucia C. Oliveira, Natália D. C. Alves e ao Núcleo de Planejamento e Desenvolvimento Institucional da Secretaria de Saúde e Defesa Civil do Estado do Rio de Janeiro pelo apoio na coleta dos materiais informativos analisados. Às vigilâncias sanitárias municipais que contribuíram para a realização deste estudo.

Resumen El artículo traza un primer perfil de producción y circulación de materiales educativos producidos y distribuidos por vigilancias municipales del Estado de Río de Janeiro, Brasil, privilegiando el tema de los alimentos, en el período 2008-2010. Para el mapeo, consultamos bases de datos y acervos de las coordinaciones de vigilancia sanitaria de los 92 municipios del estado. Las entidades de vigilancia sanitaria recibieron una carta invitación para participar en la encuesta, solicitando el envío de sus materiales educativos en las versiones física o digitalizada y el llenado de un cuestionario con preguntas de interés de la investigación: tema de los materiales, año de producción y circulación, tiraje, origen institucional, formas de cooperación, justificativa para la producción. Treinta coordinaciones respondieron y sólo nueve enviaron materiales clasificados como pertinentes para la temática de los alimentos, delineando un escenario de poca inversión en el tema, frente a su importancia para la salud pública. El análisis indicó que en la mayoría de los materiales el abordaje de la información privilegia un lenguaje técnico-científico, distante de la posibilidad de apropiación por parte de la población a que se destina; gran desigualdad en cuando a recursos de producción, con materiales de buena y mala calidad; y esfuerzo de circulación circunstancial y sujeto al proceso político y administrativo y situaciones recurrente de discontinuidad de la acción.

Palabras clave materiales educativos en salud; comunicación y salud; vigilancia sanitaria; alimentos.

\section{Notas}

1 Fundação Oswaldo Cruz, Escola Politécnica de Saúde Joaquim Venâncio, Laboratório de Vigilância em Saúde, Rio de Janeiro, RJ, Brasil.

<biancamarins@fiocruz.br>

Correspondência: Avenida Brasil, 4.365, Manguinhos, CEP 21040-360 Rio de Janeiro, RJ, Brasil.

2 Fundação Oswaldo Cruz, Instituto de Comunicação e Informação Científica e Tecnológica em Saúde, Rio de Janeiro, RJ, Brasil.

$<$ inesita@icict.fiocruz.br> 


\section{Referências}

ARAUJO, Inesita S. Materiais educativos e produção de sentidos na intervenção social. In: MONTEIRO, Simone; VARGAS, Eliane (orgs.) Educação, comunicação e tecnologia educacional: interfaces com o campo da saúde. Rio de Janeiro: Editora Fiocruz, 2006. p. 49-69.

ARAUJO, Inesita S.; CARDOSO, Janine M.; MURTINHO, Rodrigo. A comunicação no Sistema Único de Saúde: cenários e tendências. Revista Latinoamericana de Ciencias de la Comunicación, São Paulo, ano 6, n. 10, p. 104-115, 1. sem. 2010.

ARAÚJO, Nadja M. S.; ARAUJO, Inesita S. Apropriação e compartilhamento: estudos das redes de sentido da saúde a partir do programa Globo Repórter. RECIIS: Revista Eletrônica de Comunicação, Informação, Inovação em Saúde, Rio de Janeiro, v. 6, n. 4, supl., fev. 2013.

BRASIL. Ministério da Saúde. Agência Nacional de Vigilância Sanitária. Resolução RDC n. 216, de 15 de setembro de 2004. Diário Oficial da República Federativa do Brasil, Poder Legislativo, Brasília, DF, de 16 set. 2004. Disponível em: <http://portal.anvisa. gov.br/wps/wcm/connect/4a3b680040bf8 cdd8e 5dbflb0133649b/RESOLU\%C3\% $87 \% \mathrm{C} 3 \% 83 \mathrm{O}-\mathrm{RDC}+\mathrm{N}+216+\mathrm{DE}+15+\mathrm{DE}+$ SETEMBRO+DE+2004.pdf?MOD=AJPERES $>$. Acesso em: 28 out. 2015.

BRASIL. Ministério da Saúde. Secretaria de Vigilância em Saúde. Departamento de Vigilância Epidemiológica. Manual integrado de vigilância, prevenção e controle de doenças transmitidas por alimentos. Brasília: Editora do Ministério da Saúde, 2010. 158 p.: il. (Série A. Normas e Manuais Técnicos). Disponível em: < http://bvsms.saude.gov.br/bvs/ publicacoes/manual_integrado_vigilancia_ doencas_alimentos.pdf $>$. Acesso em: 28 out. 2015.

BRASIL. Agência Nacional de Vigilância Sanitária. CONFERÊNCIA NACIONAL DE VIGILÂNCIA SANITÁRIA, 1. Relatório final.
Brasília: Agência Nacional de Vigilância Sanitária, 2001. 159p. Disponível em: <http:// bvsms.saude.gov.br/bvs/publicacoes/lconf_ nac_vig_sanit_relatorio_final.pdf $>$. Acesso em: 28 out. 2015

BRASIL. Ministério da Saúde. Secretaria de Atenção à Saúde. Departamento de Atenção Básica. Política Nacional de Alimentação e Nutrição. 2. ed. rev. Brasília, DF: Ministério da Saúde, 2007. 48p. (Série B. Textos Básicos de Saúde). Disponível em: <http://conselho. saude.gov.br/biblioteca/livros/politica_ alimentacao_nutricao.pdf $>$. Acesso em: 28 out. 2015

BRASIL. Ministério do Desenvolvimento Social e Combate à Fome. Lei n. 11.346, de 15 de setembro de 2006. Cria o Sistema Nacional de Segurança Alimentar e Nutricional (Sisan) com vistas a assegurar o Direito Humano à Alimentação adequada e dá outras providências. Diário Oficial da República Federativa do Brasil, Poder Legislativo, Brasília, DF, de 18 set. 2006, p. 1. Disponível em: $<$ www.planalto.gov.br/ccivil_03/_ato20042006/2006/lei/11 1346.htm>. Acesso em: 28 out. 2015

BRASIL. Ministério da Saúde. Secretaria de Vigilância em Saúde. Relatório de pesquisa. Gestão da comunicação aplicada à vigilância em saúde: percepção dos gestores. Brasília: Ministério da Saúde, 2008. 270 p.

CASTIEL, Luis D.; VASCONCELLOS-SILVA, Paulo R. Precariedades do excesso: informações e comunicação em saúde coletiva. Rio de Janeiro: Editora Fiocruz, 2006.

CHAUD, Daniela M. A.; MARCHIONI, Dirce M. L. Nutrição e mídia: uma combinação às vezes indigesta. Higiene Alimentar, São Paulo, v. 18, n. 116/117, p. 18-22, 2004.

FREITAS, Fernanda V.; FILHO, Luiz A. R. Modelos de comunicação e uso de impressos na educação em saúde: uma pesquisa bibliográfica. Interface: Comunicação, Saúde, 
Educação, Botucatu, v. 15, n. 36, p. 243-256, jan.-mar., 2011.

GRIPPO, Monica L. V. S.; FRACOLLI, Lislaine A. A. Avaliação de uma cartilha educativa de promoção ao cuidado da criança a partir da percepção da família sobre temas de saúde e cidadania. Revista da Escola de Enfermagem, São Paulo, v. 42, n. 3, p. 430-436, 2008.

MARINS, Bianca R. A vigilância sanitária, o cidadão e o direito à comunicação: um estudo sobre a rotulagem de alimentos. 2009. 286 fls. Tese (Doutorado em Vigilância Sanitária) - Fundação Oswaldo Cruz, Instituto Nacional de Controle de Qualidade em Saúde, Rio de Janeiro, 2009.

MARQUES, Terezinha. Práticas de comunicação em vigilância sanitária: experiências e desafios. In: COSTA, Ediná A.; RANGEL-S, Maria L. (orgs.). Comunicação em vigilância sanitária: princípios e diretrizes para uma política. Salvador: EDUFBA, 2007. p. 135-150.

MONTEIRO, Simone; VARGAS, Eliane P.; CRUZ, Marly. Desenvolvimento e uso de tecnologias educacionais no contexto da Aids e da saúde reprodutiva: reflexões e perspectivas. In: MONTEIRO, Simone; VARGAS, Eliane P. (orgs.). Educação, comunicação e tecnologia educacional: interfaces com o campo da saúde. Rio de Janeiro: Editora Fiocruz, 2006. p. 27-34.

PIMENTA, Denise N., LEANDRO, Anita; SCHALL, Virgínia T. Experiências de desenvolvimento e avaliação de materiais educativos sobre saúde: abordagens sócio-históricas e contribuições da antropologia visual. In: MONTEIRO, Simone; VARGAS, Eliane P. (orgs.). Educação, comunicação e tecnologia educacional: interfaces com o campo da saúde. Rio de Janeiro: Fiocruz, 2006. p. 87-112.
RANGEL-S., Maria L.; MARQUES, Terezinha; COSTA, Ediná A. Risco, vigilância sanitária e comunicação: subsídios para uma política de proteção e promoção da saúde. In: COSTA, Ediná A.; RANGEL-S., Maria L. (orgs.). Comunicação em vigilância sanitária: princípios e diretrizes para uma política. Salvador: EDUFBA, 2007. p. 15-42.

SANTOS, Karina M. O.; FILHO, Antônio A. B. Fontes de informação sobre nutrição e saúde utilizadas por estudantes de uma universidade privada de São Paulo. Revista de Nutrição, Campinas, v. 15, n. 2, p. 201-210, 2002.

SERRA, Giane M. A.; ARAUJO, Inesita S.; SANTOS, Elizabeth M. Comer com os olhos: discursos televisivos e produção de sentidos na promoção da saúde nutricional de adolescentes. RECIIS: Revista Eletrônica de Comunicação, Informação, Inovação em Saúde, Rio de Janeiro, v. 6, n. 4, dez. 2012.

VASCONCELLOS-SILVA, Paulo R.; RIVERA, Francisco J. U.; ROZEMBERG, Brani. Próteses de comunicação e alinhamento comportamental sobre impressos hospitalares. Revista de Saúde Pública, São Paulo, v. 37, n. 4, p. 531-542, 2003.

Recebido em 30/09/2013

Aprovado em 11/03/2014 